\title{
A STUDY OF CLINICAL, METABOLIC AND ANTHROPOMETRIC PROFILE AND POSSIBLE ETIOLOGICAL FACTORS AMONG NEWLY DETECTED TYPE 2 DM IN NORTH KERALA
}

\author{
K. G. Sajeeth Kumar' ${ }^{1}$ P. K. Sasidharan², N. Anoop 3
}

1 Professor, Department of General Medicine, Government Medical College, Calicut, Kerala, India.

${ }^{2}$ Professor, Department of General Medicine, Government Medical College, Calicut, Kerala, India.

3Junioer Resident. Department of General Medicine, Government Medical College, Calicut, Kerala, India.

\section{ABSTRACT}

\section{BACKGROUND}

Type 2 diabetes is one of the leading causes for financial burden in developing countries like India. Most cases of diabetes are detected years after its onset and one or the other complication would have set in by the time of diagnosis. The proposed mechanisms of diabetes include reduced insulin secretion, increased insulin resistance, sedentary life style, obesity and inappropriate diet. Early detection of diabetes and optimal blood sugar control along with diet modification, weight reduction and management of other coexisting illnesses can delay the diabetes related complications significantly and improve the quality of life

\section{MATERIALS AND METHODS}

This is a cross sectional study of patients with type 2 diabetes detected within last 1 year who presented to General Medicine OPD or Diabetic clinic or those who were in-patients in General Medicine wards in Government Medical College, Kozhikode. 300 patients were included in the study. Data was collected by a detailed history taking, clinical and anthropometric examination, biochemical and radiological investigations.

\section{RESULTS}

Age of the patients in the study population varied from 22 to 88 years. All the 32 patients in the age group of 20-29 years had low levels of physical activity. $62.5 \%$ (20 out of the 32) of patients in the age group between 20-29 years had history of diabetes in their parents when compared only $55.5 \%$ in age group $30-49$ years and $10.2 \%$ in patients with aged 50 and above. Cereals constituted the main food item in patients in all the age groups. 269 patients (89.6\%) had cereals served 3-4 times a day. Intake of pulses was deficient in all age groups, with only 20 patients out of the $300(6.7 \%)$ having near adequate pulses intake (3-4 times/week). Only 8 out the 300 patients (2.7\%) used fruits at least 3 times a week. Fast and junk food intake was high among young individuals. 28 out of 32 patients aged 30 years or less used these at least once a day. "At-risk" waist hip ratio was seen only in 8 patients and all of them were in the age group 30-49 years. Majority (89 out of 108) of patients with age above 50 years had "excellent" waist hip ratio. Classical symptoms were less prominent in patients aged above 50 years with only 7 out of 108 (6.5\%) patients having these symptoms when compared with $27.3 \%$ patient with age less than 50 years. Microvascular complications (albuminuria, neuropathy and retinopathy) were more frequent in patients with age above 50 years. Systemic hypertension was seen in 118 patients (39.3\%), coronary artery disease in 50 patients $(16.7 \%)$, stroke in 27 patients (9\%) and obstructive sleep apnoea in 83 patients $(27.7 \%)$. 84 patients had evidence of peripheral neuropathy in the nerve conduction study.

\section{CONCLUSION}

Majority of detected diabetics were males and there is a shift in age of onset of diabetes to about 20.6 years in younger population. Most of the diabetics do not take a balanced diet and is usually having high calories and deficient in fruits and vegetables. Low levels of physical activity and diabetes seem to be associated. Only $14.3 \%$ had symptoms of diabetes, hence routine screening is necessary. Family history of diabetes is usually seen in younger onset diabetes. The "metabolically obese but normal weight phenomenon" described in Indian population is further substantiated. Most common complications in newly detected diabetes were hypertension and OSAS and most common microvascular complication was nephropathy.

\section{KEY WORDS}

Diabetes, Obesity, Waist-Hip Ratio, Hypertension, Coronary Artery Disease, Microvascular, Macrovascular, Diabetic Nephropathy HOW TO CITE THIS ARTICLE: Kumar KGS, Sasidharan PK, Anoop N. A study of clinical, metabolic and anthropometric profile and possible etiological factors among newly detected type 2 DM in North Kerala. J. Evolution Med. Dent. Sci. 2019;8(12):907-914, D0I: $10.14260 /$ jemds/2019/202

'Financial or Other Competing Interest': None.

Submission 02-02-2019, Peer Review 10-03-2019,

Acceptance 16-03-2019, Published 25-03-2019.

Corresponding Author:

Dr. K. G. Sajeeth Kumar,

Professor,

Department of General Medicine

Government Medical College,

Calicut, Kerala

India.

E-mail: kgsajeeth@yahoo.com

DOI: $10.14260 /$ jemds $/ 2019 / 202$

\section{BACKGROUND}

Type 2 diabetes accounts for about $90 \%$ of the diabetic population. The global prevalence of diabetes is increasing day by day. The prevalence estimated as $4 \%$ in 1995 and expected to be increasing to $5.4 \%$ by the year 2025.1,2 Type 2 diabetes mellitus is characterized by insulin resistance and relatively reduced insulin secretion. In the early stage of type 2 diabetes hyperglycaemia can be managed by a variety of measures and drugs that improve insulin sensitivity. As the disease progresses over years, the insulin secretion worsens, and therapy with insulin becomes necessary. ${ }^{3}$ The bad companions to type 2 diabetes are high blood pressure, 
dyslipidaemia, hyperhomocysteinaemia and smoking. Cardiovascular complications account for two third of mortality in type 2 diabetes. This is because type 2 diabetes mellitus is often the tip of iceberg of the whole realm of metabolic syndrome. So, the best approach is to consider type 2 diabetes as a constituent of the metabolic syndrome.4,5

\section{Historical Aspects}

Diabetes mellitus (DM) is one of the oldest diseases known to man. It was first reported about 3000 years ago in Egyptian manuscripts. The name Diabetes mellitus is derived from two words. One is a Greek word 'diabetes' meaning siphon - to pass through and the other is a Latin word 'mellitus' meaning sweet. The term diabetes was coined by Apollonius of Memphis at around $250 \mathrm{BC}$. Thomas Willis added the word 'mellitus' to the word diabetes in 1675. Greek physicians advised exercise to reduce polyuria. Other forms of therapy include wine, starvation diet etc. Sushruta identified diabetes and classified it as "Madhumeha". In ancient times, Indians tested for diabetes by looking the attraction for ants to patient's urine. Banting, Best and Collip purified the hormone insulin from pancreas of cows at University of Toronto. This led to the effective treatment for diabetes in 1922. The first biosynthetic human insulin - Humulin was approved to market in several countries in 1982.6,7

\section{Epidemiology}

According to the Diabetes Atlas, total number of people with diabetes in India at present is around 61.3 million is expected to rise to 101.2 million by $2030 .{ }^{1}$ Asians are more prone to diabetes and premature coronary artery disease due to the typical Asian Indian phenotype. 8 Asian diabetics had more incidence of macro and micro vascular complications at the time of diagnosis of diabetes. ${ }^{9}$

\section{Pathogenesis}

Mainly three mechanisms are proposed to explain the pathogenesis of type 2 diabetes. First, a possible genetic defect may be present. Second, insufficient beta-cell development due to in-utero malnutrition. This is called the "thrifty phenotype hypothesis."10 And the third is, unfavourable metabolic environment, especially increased glucose levels which may induce glucotoxicity and a persistent increase in NEFA levels that may induce lipotoxicity. ${ }^{11}$ Gluco-lipotoxicity and the resultant increase in inflammatory mediators are also important. Involvement of adipocyte-derived bioactive substances (Adipokines), TNF- $\alpha$, leptin, resistin and free fatty acids are found to increase insulin resistance. Three commonly encountered factors that influence insulin sensitivity are aging, exercise and dietary constituents. The causes of type 2 diabetes are multifactorial and include both genetic and environmental elements that affect beta-cell mass and function. ${ }^{12,13}$

\section{Diabetes and Obesity}

Obesity is associated with chronic diseases such as diabetes mellitus, dyslipidaemia, hypertension, sleep apnoea, cardiovascular and cerebrovascular diseases.14 Obesity, especially with visceral obesity, is associated with a persistent low-grade inflammation. ${ }^{15}$

\section{Type 2 Diabetes Mellitus and Hypertension}

Approximately $60 \%$ of type 2 diabetes patients have high blood pressure. 16 Coexistence of these two conditions increase the risk of complications. ${ }^{17}$ Target blood pressure for diabetic patients, according to the ADA is $<130 / 80$ mmHg. ${ }^{18}$ Initial treatment should include nonpharmacological measures such as weight reduction, exercise, reduced salt intake, avoiding alcohol consumption and smoking cessation. Later pharmacological treatment may be initiated. ${ }^{19}$

\section{Type 2 DM and Dyslipidaemia}

Dyslipidaemia in type 2 diabetes worsens CV risk due to increased triglycerides and LDL levels and decreased HDL cholesterol levels. These molecules predispose to early and aggressive atherosclerosis. ${ }^{20}$

\section{Type 2 DM and Diet}

There is significant association between the risk of type 2 diabetes and carbohydrate quality which is measured as Glycaemic Index. The mechanism proposed is toxicity of $\beta$ cells due to hyperglycemia. ${ }^{21,22}$ The type of fat in diet seems to have an important effect on the risk of type 2 diabetes ${ }^{23}$. Plasma 25-hydroxyvitamin D (25-OHD) has a significant protective effect on developing type 2 diabetes.24,25 Fruit intake of more than 3 servings per day is associated with a lower risk of type 2 diabetes, whereas increase in fruit juice intake was associated with an increased risk of developing type 2 diabetes. ${ }^{26}$ Various studies have shown that there is a strong association between red meat consumption and risk of type 2 diabetes. ${ }^{27,28}$ Whole grain consumption has a strong inverse association with risk of type 2 diabetes. ${ }^{29}$ White rice consumption is associated with a $17 \%$ increased risk of type 2 diabetes whereas brown rice is associated with $11 \%$ risk reduction.30,31 Sugar sweetened beverages are significantly associated with increased risk of type 2 diabetes. ${ }^{32,33}$ Analysis of diet and lifestyle risk factors showing that, those who consumed a diet having low glycaemic index, low trans fats, high cereal fibers and a high ratio of polyunsaturated to saturated fat have a lower risk of type 2 diabetes. ${ }^{34,35}$

\section{Type 2 DM and Physical Activity}

Physical activity is one of the most important factors for the prevention of development of type 2 diabetes. Studies have shown that there is significant reduction in type 2 diabetes risk factors regardless of the type of exercise. ${ }^{36,37}$ Sedentary lifestyle is positively associated with risk of developing type 2 diabetes. ${ }^{38}$

\section{The Role of Glycaemic Control}

Several clinical trials have investigated the effect of tight control of blood sugar in T2DM and cardiovascular morbidity. Intensive treatment of hyperglycaemia and maintaining HbA1c levels below 7\% early in the course of type 2 diabetes is associated with low cardiovascular risk. This early protection is postulated to be resulting from a mechanism called "metabolic memory," which means that the effect of early glycaemic environment is remembered later in target organs resulting in long-term deleterious or protective effects. 39,40 


\section{MATERIALS AND METHODS}

The study was a Cross sectional Analysis with special emphasis on clinical and metabolic profile of 300 consecutive patients with newly detected Type 2 DM. The study was also aimed at detecting the early complications in asymptomatic newly detected Type $2 \mathrm{DM}$ individuals. They were diagnosed with FPG $>126 \mathrm{mg} \%$ or RPG $>200 \mathrm{mg} \%$ with symptoms of DM or $2 \mathrm{hr}$ PPG $>200 \mathrm{mg} \%$ after food or with $75 \mathrm{mg}$ glucose load were enrolled for the study.

The patients were briefed about the study and written consent was obtained. Those who signed the consent were subjected to a detailed clinical examination and anthropometric measurement. Blood samples were collected including fasting plasma for biochemical analysis to be done from Central lab. A detailed personal and Family history and the risk factor profile of the patient were collected using a pretested structured questionnaire. Patients were also subjected to USG abdomen and KUB for evaluation of renal and hepatic echotexture.

In cases where type determination was difficult, patients were subjected to C-peptide and GAD antibody to rule out accidental inclusion of Type $1 \mathrm{DM}$.

\section{RESULTS}

\section{Pre-Operative Analysis}

Total 300 cases were studies.

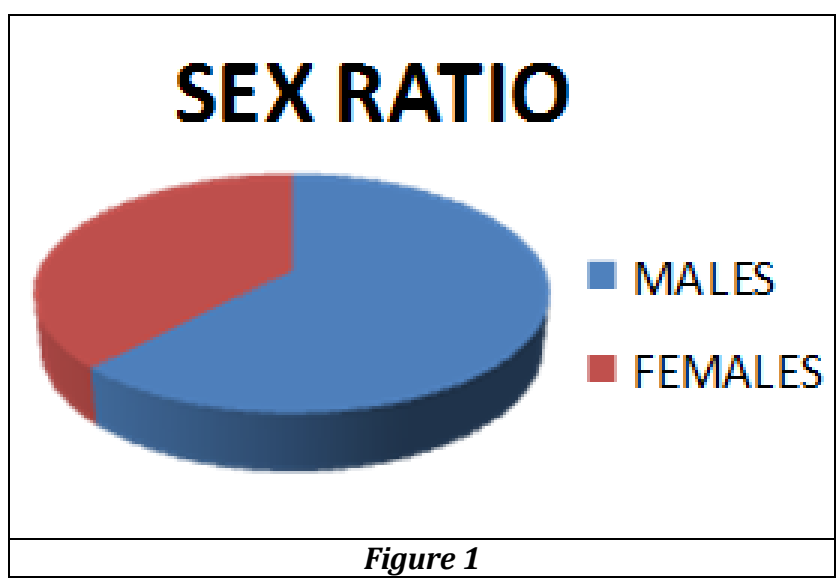

Age of the patients in the study population varied from 22 to 88 years. Mean age was 46.4 years with a standard deviation of 13.3. Out of the 300 patients studied $186(62 \%)$ were males and 114 (38\%) were females. Majority of the patients with newly diagnosed type two diabetes mellitus were in the age group 30-49 years.

\begin{tabular}{|c|c|c|}
\hline Age (Yrs.) & Frequency & Percent \\
\hline 20-29 Years & 32 & 10.7 \\
\hline 30-49 Years & 160 & 53.3 \\
\hline 50 Years and Above & 108 & 36.0 \\
\hline Total & $\mathbf{3 0 0}$ & $\mathbf{1 0 0 . 0}$ \\
\hline \multicolumn{3}{|c|}{ Table 1 } \\
\hline
\end{tabular}

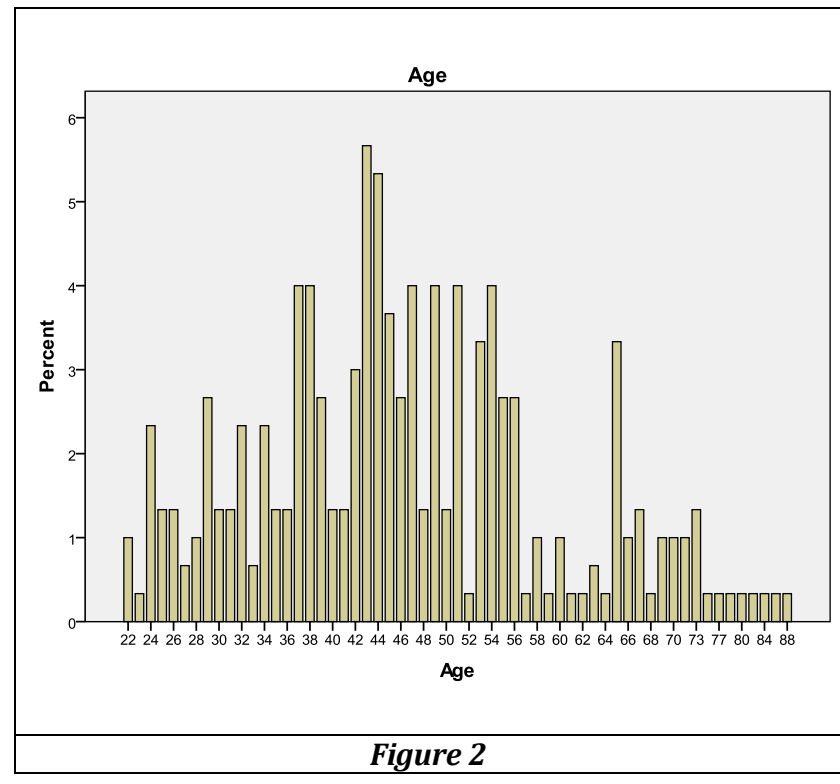

\section{Anthropometric Parameters}

Only 40 patients $(13.3 \%)$ met the cut off for obesity for Indian population i.e. $27.5 \mathrm{~kg} / \mathrm{m}^{2}$ and only 8 patients $(2.7 \%)$ had the "at - risk" waist to hip ratio defined by $>0.95$ in males and 0.86 in females

\begin{tabular}{|c|c|c|c|c|}
\hline \multirow{2}{*}{$\begin{array}{c}\text { Age } \\
\text { Group }\end{array}$} & $\begin{array}{c}\text { Normal } \\
(<\mathbf{2 3})\end{array}$ & $\begin{array}{c}\text { Over Weight } \\
(\mathbf{2 3 - 2 7 . 4 )}\end{array}$ & $\begin{array}{c}\text { Obese } \\
(\mathbf{> 2 7 . 5})\end{array}$ & \\
\hline 20-29 Years & 12 & 16 & 4 & 32 \\
\hline 30-49 Years & 76 & 48 & 36 & 160 \\
\hline 50 Years \& Above & 71 & 37 & 0 & 108 \\
\hline Total & $\mathbf{1 5 9}$ & $\mathbf{1 0 1}$ & $\mathbf{4 0}$ & $\mathbf{3 0 0}$ \\
\hline \multicolumn{5}{|c|}{ Table 2 } \\
\hline
\end{tabular}

\begin{tabular}{|c|c|c|c|c|c|}
\hline \multirow{2}{*}{$\begin{array}{c}\text { Age } \\
\text { Group }\end{array}$} & \multicolumn{4}{|c|}{ Waist Hip Ratio } & \multirow{2}{*}{ Total } \\
\hline & Excellent & Good & Average & At Risk & \\
\hline $\begin{array}{l}20-29 \\
\text { Years }\end{array}$ & 0 & 20 & 12 & 0 & 32 \\
\hline $\begin{array}{l}30-49 \\
\text { Years }\end{array}$ & 48 & 60 & 40 & 8 & 156 \\
\hline $\begin{array}{l}50 \text { Years } \\
\text { and } \\
\text { Above }\end{array}$ & 89 & 19 & 0 & 0 & 108 \\
\hline Total & 137 & 99 & 52 & 8 & 296 \\
\hline \multicolumn{6}{|c|}{ Table 3} \\
\hline
\end{tabular}

"At-risk" waist hip ratio surprisingly was seen more in the productive age group, again a reflection of the preference for sedentary jobs and unhealthy food habits. $22.5 \%$ of those who were in the productive age group were obese, which suggests the preference to sedentary jobs. This can lead onto many lifestyle diseases.

\section{Physical Activity}

Out of the 300 study subjects, 171 patients were engaged in occupation which involved only low levels of physical activity. All the patients with newly detected diabetes younger than 30 years were engaged in activities that involve only low level of physical activity. Female patients with newly detected diabetes were also more engaged in occupation that involve low level of physical activity. 


\begin{tabular}{|c|c|c|c|c|}
\hline \multirow{2}{*}{ Sex } & \multicolumn{3}{|c|}{ Physical Activity } & \multirow{2}{*}{ Total } \\
\cline { 2 - 4 } & Heavy & Low & Moderate & \\
\hline Female & 14 & 86 & 14 & 114 \\
\hline Male & 35 & 95 & 56 & 186 \\
\hline Total & $\mathbf{6 9}$ & $\mathbf{1 7 1}$ & $\mathbf{6 0}$ & $\mathbf{3 0 0}$ \\
\hline \multicolumn{4}{|c|}{ Table 4 } \\
\hline
\end{tabular}

\section{Diet}

Cereals constituted the main food item in patients in all the age groups. Intake of pulses was deficient in all age groups, with only 20 patients out of the $300(6.7 \%)$ having near adequate pulses intake (3-4 times/week). Majority of our population do not meet the requirements of a balanced diet. $62.5 \%$ of patients in the age group 20-29 years used vegetables only 1 or 2 times a week when compared with $82.5 \%$ in age group 30-49 years and all patients with age 50 years and above. This difference was statistically significant with $p$ value less than 0.001 . 8 out the 300 patients $(2.7 \%)$ used fruits at least 3 times a week. Fast and junk food intake was high among young individuals. 28 out of 32 patients aged 30 years or less used these at least once a day. This observation was statistically significant with a $p$ value less than 0.001 . The increasing dependence of fast and junk foods could take a toll on the overall health status of the coming generation and is an alarming observation.

\begin{tabular}{|c|c|c|c|c|c|c|c|}
\hline \multirow[b]{2}{*}{$\begin{array}{l}\text { Age } \\
\text { Group }\end{array}$} & \multicolumn{6}{|c|}{ Fast and Junk Foods } & \multirow[b]{2}{*}{ Total } \\
\hline & $\dot{0}^{\circ}$ & 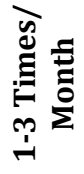 & 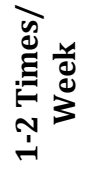 & 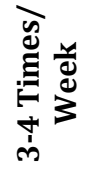 & 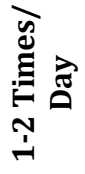 & 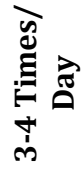 & \\
\hline $\begin{array}{l}20-29 \\
\text { Years }\end{array}$ & 0 & 0 & 0 & 4 & 28 & 0 & 32 \\
\hline $\begin{array}{c}30-49 \\
\text { Years }\end{array}$ & 0 & 0 & 28 & 76 & 48 & 8 & 160 \\
\hline $\begin{array}{c}50 \\
\text { Years } \\
\text { and } \\
\text { Above }\end{array}$ & 23 & 29 & 52 & 4 & 0 & 0 & 108 \\
\hline Total & 23 & 29 & 80 & 84 & 76 & 8 & 300 \\
\hline
\end{tabular}

\begin{tabular}{|c|c|c|c|}
\hline \multirow{2}{*}{ Age Group } & \multicolumn{2}{|c|}{ Vegetables } & \multirow{2}{*}{ Total } \\
\cline { 2 - 4 } & $\begin{array}{c}\mathbf{3 - 4} \\
\text { Times/Week }\end{array}$ & $\begin{array}{c}\mathbf{1 - 2} \\
\text { Times/Week }\end{array}$ & \\
\hline 20-29 Years & 12 & 20 & 32 \\
\hline 30-49 Years & 28 & 132 & 160 \\
\hline 50 Years and Above & 0 & 108 & 108 \\
\hline Total & $\mathbf{4 0}$ & $\mathbf{2 6 0}$ & $\mathbf{3 0 0}$ \\
\hline \multicolumn{3}{|c|}{ Table 6 } \\
\hline
\end{tabular}

\section{Fruits Consumption}

\begin{tabular}{|c|c|c|}
\hline & Frequency & Percent \\
\hline 1-3 Times/Month & 30 & 10.0 \\
\hline 1-2 Times/Week & 262 & 87.3 \\
\hline 3-4 Times/Week & 8 & 2.7 \\
\hline Total & $\mathbf{3 0 0}$ & $\mathbf{1 0 0 . 0}$ \\
\hline \multicolumn{3}{|c|}{ Table 7 } \\
\hline
\end{tabular}

73 patients $(24.3 \%)$ were smokers and 48 patients (16.0\%) regularly used alcohol. All the patients with alcohol use were male. Out the 73 smokers, 70 were males. Most common was inhaled corticosteroids which were used by 16 patients. The mean fasting plasma glucose was $210.9 \mathrm{mg} / \mathrm{dl}$, mean post prandial plasma glucose was $302.4 \mathrm{mg} / \mathrm{dl}$ and mean HbA1c was 8.5. 261 patients (87\%) out of the 300 patients in our study population were below poverty line as per guidelines of by the government of India.

Classical symptoms were less prominent in patients aged above 50 years with only 7 out of 108 (6.5\%) patients having these symptoms when compared with $27.3 \%$ patient with age less than 50 years. This observation had a p value less than 0.001 . Mean total cholesterol was $216 \mathrm{mg} / \mathrm{dl}$, HDL was 43 $\mathrm{mg} / \mathrm{dl}$, LDL was $141 \mathrm{mg} / \mathrm{dl}$ and triglyceride was $161 \mathrm{mg} / \mathrm{dl}$.

\section{Family History Diabetes for Parents}

$62.5 \%$ (20 out of the 32) of patients in the age group between 20-29 years had history of diabetes for their parents when compared only $55.5 \%$ in age group $30-49$ years and $10.2 \%$ in patients with aged 50 and above. This observation is statistically significant with $\mathrm{p}$ value less than 0.001 . A strong family history can contribute to earlier occurrence of type 2 diabetes mellitus in subsequent generations.

\begin{tabular}{|c|c|c|c|c|}
\hline \multirow{2}{*}{ Age Group } & \multicolumn{3}{|c|}{$\begin{array}{c}\text { Family History of Diabetes } \\
\text { Mellitus for Parents }\end{array}$} & \multirow{2}{*}{ Total } \\
\cline { 2 - 4 } & No. & $\begin{array}{c}\text { One } \\
\text { Parent }\end{array}$ & $\begin{array}{c}\text { Two } \\
\text { Parents }\end{array}$ & \\
\hline 20-29 Years & 12 & 12 & 8 & 32 \\
\hline 30-49 Years & 72 & 76 & 12 & 160 \\
\hline $\begin{array}{c}\text { 50 Years and } \\
\text { Above }\end{array}$ & 97 & 11 & 0 & 108 \\
\hline Total & $\mathbf{1 8 1}$ & $\mathbf{9 9}$ & $\mathbf{2 0}$ & $\mathbf{3 0 0}$ \\
\hline \multicolumn{5}{|c|}{ Table 8 } \\
\hline
\end{tabular}

\section{Comorbidities}

Systemic hypertension was seen in 118 patients (39.3\%), coronary artery disease in 50 patients $(16.7 \%)$, stroke in 27 patients (9\%) and obstructive sleep apnoea in 83 patients (27.7\%). Systemic hypertension, coronary artery disease and stroke were more common in patients with advanced age.

\section{COMORBIDITIES}

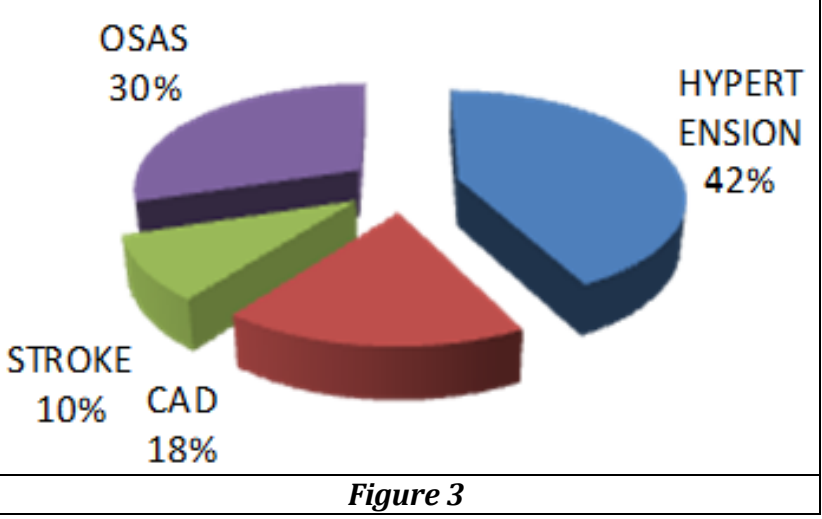

\section{Microvascular Complications}

Microvascular complications (albuminuria, neuropathy and retinopathy) were more frequent in patients with age above 50 years. This observation was statistically significant with $\mathrm{p}$ value less than 0.001 for all the three complications. 


\begin{tabular}{|c|c|c|c|c|}
\hline \multirow{2}{*}{ Age Group } & \multicolumn{3}{|c|}{ Urine Albumin Creatinine Ratio } & \multirow{2}{*}{ Total } \\
\cline { 2 - 4 } & $\mathbf{3 0 - 3 0 0}$ & $\mathbf{3 0 0}$ & $<\mathbf{3 0}$ & \\
\hline 20-29 Years & 0 & 0 & 32 & 32 \\
\hline 30-49 Years & 40 & 0 & 120 & 160 \\
\hline $\begin{array}{c}\text { 50 Years and } \\
\text { Above }\end{array}$ & 47 & 8 & 53 & 108 \\
\hline Total & $\mathbf{8 7}$ & $\mathbf{8}$ & $\mathbf{2 0 5}$ & $\mathbf{3 0 0}$ \\
\hline \multicolumn{6}{|c|}{ Table 9 } \\
\hline
\end{tabular}

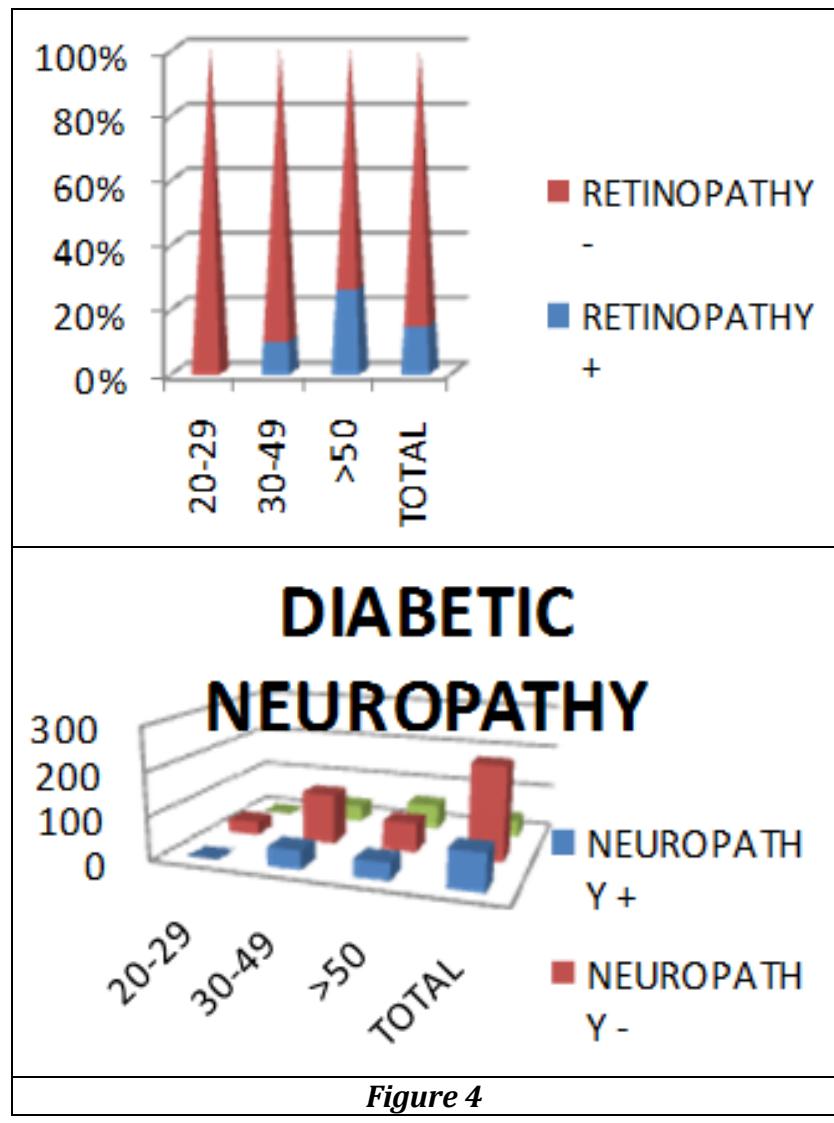

\section{Fatty Liver}

Fatty liver was seen in half of the patients below 30 years of age when screened with USG abdomen, and this increase in the frequency in young patients was statistically significant with $\mathrm{p}$ value less than 0.001 .

\begin{tabular}{|c|c|c|c|}
\hline \multirow{2}{*}{ Age Group } & \multicolumn{2}{|c|}{ Fatty Liver } & \multirow{2}{*}{ Total } \\
\cline { 2 - 3 } & No & Yes & \\
\hline 20-29 Years & 16 & 16 & 32 \\
\hline 30-49 Years & 112 & 48 & 160 \\
\hline 50 Years and Above & 93 & 15 & 108 \\
\hline Total & $\mathbf{2 2 1}$ & $\mathbf{7 9}$ & $\mathbf{3 0 0}$ \\
\hline \multicolumn{3}{|c}{ Table 10 } \\
\hline
\end{tabular}

\section{DISCUSSION}

The study was conducted on recently diagnosed diabetics with an intention to look into the aetiological factors/risk factors for development of type 2 diabetes and to study their clinical profile. Age of the newly detected diabetics varied from 22 to 88 years with a mean of 46.4 years. Majority of the newly diagnosed Type 2 diabetes mellitus were in the age group 30-49 years. This observation points towards the increasing impact of disease in the community, especially the younger ones. With the development of Diabetes, large number of patients in this group, who have only reached the midway of the expected life expectancy, will invariably develop microvascular or macrovascular complications.

261 patients (87\%) out of the 300 newly detected diabetics were below poverty line as per criteria decided by the government of India. This observation cannot be extrapolated to the community, as ours was a hospital-based study, and majority of the patients seeking health care from our hospital are from lower economic class. But still it underscores the fact that diabetes is not a disease of the rich alone.

Out of the 300 newly detected diabetics, 171 patients were engaged in occupations which involved only very low levels of physical activity. All the patients younger than 30 years were engaged in activities that involved only low physical activity. This point to the fact that low physical activity could be an important contributing factor for the earlier appearance of diabetes in the current generation. This emphasise the importance of health education regarding the importance of physical activities

A good majority of the patients did not meet the cut off for obesity for Indian population and the "at-risk" waist hip ratio defined as 0.9 in males and 0.85 in females. This observation underlines the "metabolically obese but normal weight" phenomenon described in Indian population.

Regarding diet vegetables consumption among the newly detected diabetics it was far below satisfactory levels among all the newly detected diabetics. Less vegetable consumption by younger generation is one of the most alarming faulty food habits that could contribute to early onset of diabetes mellitus. There are various reasons for less vegetable consumption in north Kerala. Breakfast is entirely constituted by carbohydrates in normal Kerala diet. If at all they claim they eat vegetables, it is in the form of potato and tubers, which are considered as vegetables by the ignorant people. The quantity of vegetable consumed is only minimal during a meal when compared with the quantity of carbohydrates consumed in the form of cereals. Lack of awareness and lack of health education in this respect is responsible for the population to continue in this diet pattern. Again, several agricultural, educational, revenue and social reforms are needed to address this issue to prevent the diabetic epidemic in India. Only 8 out the 300 newly detected diabetics $(2.7 \%)$ consumed fruits at least 3 times a week. The main limiting factor of this important source of vitamins and minerals is the cost. Red meat consumption in younger age group is an important contributor to fatty liver and resultant insulin resistance. Fast food and junk food intake was high among young individuals. 28 out of 32 patients of age less than 30 years diagnosed with diabetes consumed these at least once a day. The overall dependence on junk food and fast food has increased over recent years especially in the working-class population, leading to unnecessary increase in caloric intake with the resultant lifestyle diseases including diabetes mellitus

Family history of diabetes for parents was present in $40 \%$ of patients. The percentage of patients with family history is less when compared with other Indian studies, for example in another study which involving 4600 patients, $64 \%$ had family history. Polygenic pattern of inheritance is supposed to contribute for the family history of diabetes, but it cannot account for the dramatic increase in the prevalence of diabetes to several folds in the population in the last four 
decades. Occurrence of diabetes by a mean of 20.6 years early to the preceding generation is an unambiguous pointer towards the unhealthy diet and lifestyle in the new generation. $62.5 \%$ (20 out of the 32 ) of patients in the age group between 20-29 years had a history of diabetes for their parents when compared with only $55.5 \%$ in the age group $30-49$ years and $10.2 \%$ in patients with age 50 and above ( $p$ value less than 0.001 ). This suggests that family history is an important risk factor for occurrence of diabetes at an earlier age. This could be because they follow the unhealthy diet and lifestyle habits of their parents unknowingly.

Alcoholism, smoking and obesity are associated with unhealthy lifestyle and they contribute to the development of diabetes directly or indirectly.

Classical symptoms were less prominent in patients above 50 years with only 7 out of $108(6.5 \%)$ patients having these symptoms when compared with $27.3 \%$ patient with age less than 50 years. This would necessitate mandatory blood sugar estimation in elderly individuals $>50$ years attending health care for other reasons also, as those with diabetes are often asymptomatic.

A high prevalence of systemic hypertension, coronary artery disease and stroke was noted in the study subjects with recent onset diabetes. Prevalence of these associated co morbidities increased with the age, because age is one the important risk factor for all these diseases and possibly because of increase in the number of years during which the individual was exposed to the faulty lifestyle. The presence of multiple co-morbidities will have an adverse effect on the outcome of diabetes mellitus.

There is a substantial population of individuals with diabetes who are also hypothyroid. Co-existence of hypothyroidism in diabetic patients can add on to the metabolic insult significantly.

Microvascular complications (Albuminuria, neuropathy and retinopathy) were more frequent in patients with age above 50 years. This observation was statistically significant with $\mathrm{p}$ value less than 0.001 for all the three complications. Mostly, this is due to either undetected diabetes or poorly controlled long standing diabetes.

Fatty liver was seen in half of the newly detected diabetics below 30 years of age when screened with USG abdomen, and this increased frequency in young patients with diabetes was statistically significant with $\mathrm{p}$ value less than 0.001 . This again is a reflection of the changing dietary patterns in Kerala and more dependence of junk foods and fast foods and resultant overeating and lack of adequate exercise in the younger age group who now have multiple comorbidities due to the wrong dietary and lifestyle habits.

\section{CONCLUSION}

Majority of the patients with newly diagnosed type 2 diabetes mellitus were males (62\%) between 30-49 years of age. Occurrence of diabetes by a mean of 20.6 years earlier to the preceding generation is the unambiguous pointer towards the unhealthy lifestyle in the new generation. There was significant association between low levels of physical activity and an earlier age of development of diabetes. Low intake of fruits and vegetables were observed in majority of newly detected diabetes patients. Those who had early onset of diabetes had the lowest consumption of vegetables. High calorie carbohydrate diets, red meat consumption and junk food intake was observed among the newly detected diabetics. Only $14.3 \%$ patients had the classical symptoms of diabetes. These symptoms were even less common in patients older than 50 years of age.

There was family history of diabetes in $39.7 \%$ of patients with newly detected diabetes, mostly among patients of age 20-29 years. The "metabolically obese but normal weight" phenomenon described in Indian population is further substantiated in our study. Abnormal waist-hip ratio was seen in new onset diabetes mellitus. Normal waist hip ratio was more common in elderly with new onset diabetes mellitus. Fatty liver was observed in $50 \%$ of the young diabetics. The most common co-morbidities in new onset diabetes were systemic hypertension and obstructive sleep apnoea. Hypertension, coronary artery disease and stroke were more common in those with advanced age at diagnosis of diabetes. The most common micro vascular complication seen at diagnosis was nephropathy (Albuminuria) and the presence of microvascular complications was significantly more common in patients above 50 years of age. There is a substantial population of individuals with diabetes who are also hypothyroid. Co-existence of hypothyroidism in diabetic patients can add on to the metabolic insult significantly.

\section{Recommendations}

The observations underline the importance of health education and life style modification targeting youngsters. Several social, educational, financial and agricultural reforms are necessary to improve the dietary habits, exercise, and to promote good lifestyle to prevent diabetes and the other comorbidities which tend to come together.

\section{Ethical Approval}

All procedures performed in studies involving human participants were in accordance with the ethical standards of the institutional and/or national research committee and with the 1964 Helsinki declaration and its later amendments or comparable ethical standards. No special invasive procedure has been carried out for the purpose of this study among any of the study subjects. This article does not contain any study involving animals performed by any of the authors.

\section{Informed Consent}

Informed consent was obtained from all individual participants included in the study.

\section{REFERENCES}

[1] Wild S, Roglic G, Green A, et al. Global prevalence of diabetes: estimates for the year 2000 and projections for 2030. Diabetes Care 2004;27(5):1047-53.

[2] Global burden of diabetes. International Diabetes federation. Diabetic atlas 5th edn. Brussels: 2011. http://www.idf.org/diabetesatlas.

[3] Zimmet P, Alberti KG, Shaw J. Global and societal implications of the diabetes epidemic. Nature 2001;414(6865):782-7.

[4] Tabak AG, Brunner EJ, Miller MA, et al. Low serum adiponectin predicts 10-year risk of type 2 diabetes and HbA1c independently of obesity, lipids and inflammation: Whitehall II study. Horm Metab Res 2009;41(8):626-9. 
[5] U.K. prospective diabetes study 16. Overview of six years' therapy of type 2 diabetes - a progressive disease. UKPDS Group. Diabetes 1995;44(11):124958.

[6] Sasidharan PK. Doctor's Pocket Companion. Chapter 34. Diabetes Mellitus: Can't we prevent it? 1st edn. Jaypee Brothers Medical Publishers 2006: p. 794.

[7] Ahmed AM. History of diabetes mellitus. Saudi Med J 2002;23(4):373-8.

[8] Matheus AS, Tannus LR, Cobas RA, et al. Impact of diabetes on cardiovascular disease: an update. Article ID 653789, Int J Hypertens 2013;2013: p. 15.

[9] Mohan V, Sandeep S, Deepa R, et al. Epidemiology of type 2 diabetes: Indian scenario. Indian J Med Res 2007;125(3):217-30.

[10] Polonsky KS. Lilly Lecture 1994. The beta-cell in diabetes: from molecular genetics to clinical research. Diabetes 1995;44(6):705-17.

[11] Hales CN, Ozanne SE. For debate: fetal and early postnatal growth restriction lead to diabetes, the metabolic syndrome and renal failure. Diabetologia 2003;46(7):1013-9.

[12] Matsuda M, DeFronzo RA. Insulin sensitivity indices obtained from oral glucose tolerance testing: comparison with the euglycemic insulin clamp. Diabetes Care 1999;22(9):1462-70.

[13] Chowdhary TA, Lasker SS. Complications and cardiovascular risk factors in South Asians and Europeans with early-onset type 2 diabetes. Q J Med 2002;95(4):241-6.

[14] Greenberg AS, McDaniel ML. Identifying the links between obesity, insulin resistance and $\beta$-cell function: potential role of adipocyte-derived cytokines in the pathogenesis of type 2 diabetes. Eur J Clin Invest 2002;32(Suppl 3):24-34.

[15] Poirier P, Giles TD, Bray GA, et al. Obesity and cardiovascular disease: pathophysiology, evaluation, and effect of weight loss. An update of the 1997 American Heart Association Scientific Statement on obesity and heart disease from the obesity committee of the council on nutrition, physical activity and metabolism. Circulation 2006;113(6):898-918.

[16] Knowler WC, Fowler SE, Hamman RF, et al. 10-year follow-up of diabetes incidence and weight loss in the Diabetes Prevention Program Outcomes Study. Lancet 2009;374(9702):1677-86.

[17] American Diabetes Association. Treatment of hypertension in diabetes. Diabetes Care 1993;16(10):1394-401.

[18] Turner R, Stratton I, Fright V, et al. Hypertension in Diabetes study (HDS): I. Prevalence of hypertension in newly presenting type 2 diabetic patients and the association with risk factors for cardiovascular and diabetic complications. J Hypertens 1993;11(3):30917.

[19] Patel A, ADVANCE Collaborative Group, MacMohan S, et al. Effects of a fixed combination of perindopril and indapamide on macrovascular and microvascular outcomes in patients with type 2 diabetes mellitus (the ADVANCE trial): a randomised controlled trial. Lancet 2007;370(9590):829-40.
[20] The ACCORD Study Group, Cushman WC, Evans GW, et al. Effects of intensive blood pressure control in type 2 diabetes mellitus. N Eng J Med 2010;362(17):1575-85.

[21] Chan JM, Rimm EB, Colditz GA, et al. Obesity, fat distribution, and weight gain as risk factors for clinical diabetes in men. Diabetes Care 1994;17(9):961-9.

[22] Schulze MB, Liu S, Rimm EB, et al. Glycemic index, glycemic load, and dietary fiber intake and incidence of type 2 diabetes in younger and middle-aged women. Am J Clin Nutr 2004;80(2):348-56.

[23] Bhupathiraju SN, Tobias DK, Malik VS, et al. Glycemic index, glycemic load and risk of type 2 diabetes: results from 3 large US cohorts and an updated metaanalysis. Am J Clin Nutr 2014;100(1):218-32.

[24] Risérus U, Willett WC, Hu FB. Dietary fats and prevention of type 2 diabetes. Prog Lipid Res 2009;48(1):44-51.

[25] Pittas AG, Sun Q, Manson JE, et al. Plasma 25hydroxyvitamin D concentration and risk of incident type 2 diabetes in women. Diabetes Care 2010;33(9):2021-3.

[26] Pittas AG, Dawson-Hughes B, Li T, et al. Vitamin D and Calcium intake in relation to type 2 diabetes in women. Diabetes Care 2006;29(3):650-6.

[27] Cooper AJ, Forouhi NG, Ye Z, et al. Fruit and vegetable intake and type 2 diabetes: EPIC-InterAct prospective study and meta-analysis. Eur J Clin Nutr 2012;66(10):1082-92.

[28] Schulze MB, Manson JE, Willett WC, et al. Processed meat intake and incidence of type 2 diabetes in younger and middle-aged women. Diabetologia 2003;46(11):1465-73.

[29] Rajpathak S, Ma J, Manson J, et al. Iron intake and the risk of type 2 diabetes in women: a prospective cohort study. Diabetes Care 2006;29(6):1370-6.

[30] Liu S, Manson JE, Stampfer MJ, et al. A prospective study of whole-grain intake and risk of type 2 diabetes mellitus in US women. Am J Public Health 2000;90(9):1409-15.

[31] Sun Q, Spiegelman D, van Dam RM, et al. White Rice, Brown Rice, and risk of type 2 diabetes in US men and women. Arch Intern Med 2010;170(11):961-70.

[32] Hu EA, Pan A, Malik V, et al. White rice consumption and risk of type 2 diabetes: meta-analysis and systematic review. BMJ 2012;344:e1454.

[33] De Koning L, Fung TT, Liao X, et al. Low-carbohydrate diet scores and risk of type 2 diabetes in men. Am J Clin Nutr 2011;93(4):844-50.

[34] Hu FB, Manson JE, Stampfer MJ, et al. Diet, lifestyle and the risk of type 2 diabetes mellitus in women. $\mathrm{N}$ Engl J Med 2001;345(11):790-7.

[35] Malik VS, Fung TT, van Dam RM, et al. Dietary patterns during adolescence and risk of type 2 diabetes in middle-aged women. Diabetes Care 2012;35(1):12-8.

[36] Qi L, Hu FB. Dietary glycemic load, whole grains and systemic inflammation in diabetes: the epidemiological evidence. Curr Opin Lipidol 2007;18(1):3-8.

[37] Mekary RA, Giovannucci E, Cahill L, et al. Eating patterns and type 2 diabetes risk in older women: breakfast consumption and eating frequency. Am J Clin Nutr 2013;98(2):436-43. 
[38] Ley SH, Hamdy O, Mohan V, et al. Prevention and management of type 2 diabetes: dietary components and nutritional strategies. Lancet 2014;383(9333):1999-2007.

[39] Grøntved A, Pan A, Mekary RA, et al. Musclestrengthening and conditioning activities and risk of type 2 diabetes: a prospective study in two cohorts of US women. PLoS Med 2014;11(1):e1001587.
[40] The Action to Control Cardiovascular Risk in Diabetes Study Group, Gerstein HC, Miller ME, et al. Effects of Intensive glucose lowering in type 2 diabetes. $\mathrm{N}$ Engl J Med 2008;358(24):2545-59. 